\title{
O Exercício da Democracia através da Participação Social nos Conselhos da Criança e do Adolescente: Estudo de Caso no Município de Paulo Afonso - BA
}

\author{
Fábio Evaristo dos Santos ${ }^{1}$; Deise Cristiane do Nascimento ${ }^{2}$
}

Resumo: O estudo teve o objetivo de examinar o impacto da participação social no Conselho Municipal de Direito da Criança e do Adolescente, identificar como se dá o controle social na perspectiva do exercício democrático na gestão pública; informar ações que demonstrem a participação social no planejamento de políticas públicas para infância e adolescência em Paulo Afonso e verificar o impacto das ações no Conselho, na perspectiva de efetivação do controle social e participação democrática no Município. A participação social surgiu para aproximar a esfera estatal da dinâmica social. Esses conselhos, com a composição do governo e da sociedade civil, sua criação foi intitulada como imprescindível na rede de proteção dos municípios. Realidade vivenciada pelo município de Paulo Afonso e tal afirmativa fora apresentada por meio de documentos comprobatórios de suas políticas de desenvolvimento, sendo referência no semiárido quanto ao fortalecimento de políticas de proteção aos direitos da criança e do adolescente.

Palavras-chave: Democracia. Controle Social. Conselho Municipal. Participação Social. Estado.

\section{Exercise of Democracy Through Participation in Social Rights of Municipal Councils of Children and Adolescents: Case Study Municipality of Paulo Afonso - BA}

\begin{abstract}
Abstrac: This study aimed to study the impact of social participation in the Municipal Council of Rights of Children and Adolescents, identify how is social control in view of the democratic exercise in public administration; inform actions that demonstrate the social participation in the planning of public policies for children and adolescents in Paulo Afonso and verify the impact of actions the Council, the effective perspective of social control and democratic participation in the municipality. Social participation emerged to bring the state sphere of social dynamics. These councils, with the government's composition and civil society, its creation was titled as essential in protecting network of municipalities. Reality experienced by the city of Paulo Afonso and this statement was presented by documents supporting their development policies, and reference in the semi-arid region in strengthening protection policies for child and adolescent rights.
\end{abstract}

Keywords: Democracy. Social control. City Council. Social participation. State.

\section{Introdução}

A interação social é essencial para a humanidade e, para tal, se faz necessária a coexistência harmoniosa entre pessoas de diferentes crenças e classes sociais que precisam gerenciar conflitos oriundos da convivência em ambientes de pluralidade cultural.

\footnotetext{
${ }^{1}$ Graduado em Administração de Empresas com Habilitação em Marketing - Faculdade sete de Setembro - FASETE 
Id on Line Revista Multidisciplinar e de Psicoloqia

Id on Line Multidisciplinary Journal and Psycology

${ }^{2}$ Professora orientadora do Curso de Pós-Graduação em Gestão Pública Municipal da UNIVASF. Professora auxiliar da Faculdade de Ciências Aplicadas de Petrolina. E-mail: deise.nascimento@facape.br.

De acordo com DALLARI:

Os seres humanos vivem juntos, vivem em sociedade não apenas porque escolheram esse modo de vida, mas porque a vida em sociedade é uma necessidade na natureza humana. Assim, por exemplo, se dependesse apenas da vontade, seria possível uma pessoa rica isolar-se em algum lugar, onde tivesse armazenada grande quantidade de alimentos. Mas essa pessoa estaria, em pouco tempo, sentindo falta de companhia, sofrendo a tristeza e a solidão, precisando de alguém com quem falar e trocar ideias necessitada de dar e receber afeto. E muito provavelmente ficaria louca se continuasse sozinha por muito tempo. (DALLARI, 2004, p.27)."

$\mathrm{Na}$ sociedade se encontram diversas pessoas com ideais diferentes ligadas entre si por uma cadeia de dependências, gerando a necessidade de auxílio mútuo para que se atinjam seus objetivos. A ordem social pode ser promovida de diversas maneiras, tais como: leis, formas de organização e comportamento, respeitando o exercício da democracia.

"Democracia significa identidade entre governantes e governados, entre sujeito e objeto do poder, governo do povo sobre o povo, no que, obviamente, se percebe um viés político no sentido do autogoverno republicano". (COSTA, 2010, p.87).

A democracia exige regras estabelecidas pelo direito para viabilizar a política democrática. Estas regras buscam garantir os direitos a todos os indivíduos, garantindo a democracia.

A Organização das Nações Unidas (ONU), em 1948, aprovou a Declaração Universal dos Direitos Humanos, que cita em seu artigo I: "todos os seres humanos nascem livres e iguais em dignidade e direitos.” (Declaração dos Direitos Humanos, 1948)

Sob esta ótica deve-se reconhecer que todas as crianças e adolescentes, enquanto sujeitos de direitos, devem ser compreendidos como detentores de todos os direitos da pessoa humana.

Dessa forma, este trabalho busca demonstrar como os conselhos municipais têm procurado garantir a dignidade e igualdade de direitos para crianças e adolescentes através das políticas públicas adequadas.

Estes conselhos são instâncias normativas, deliberativas e controladoras da política municipal de atendimento. Seu funcionamento é regulamentado por regimento interno, obedecendo diretrizes traçadas pela lei municipal e por outros diplomas legais aplicáveis à matéria.

Os conselhos municipais têm por finalidade o controle social da política municipal, bem como sugerir a adoção de políticas públicas municipais que visem assegurar direitos à criança e ao adolescente.

Partindo dessa determinação o Conselho proporciona uma maior participação com alternativas de elaboração e fiscalização de políticas públicas, criando espaços de debate, estabelecendo 
Id on Line Revista Multidisciplinar e de Psicoloqia

Id on Line Multidisciplinary Journal and Psycology

mecanismos de negociação e pactuação, penetrando a lógica burocrática estatal para transformá-la e exercer o controle socializado das ações e deliberações governamentais.

Dessa forma, o problema em estudo caracteriza-se pela seguinte pergunta: Ocorre participação social nos Conselhos Municipais de Direito da Criança e Adolescentes do Município de Paulo Afonso, Estado da Bahia?

A finalidade geral desse estudo está na análise do impacto da participação social no Conselho Municipal de Direito da Criança e do Adolescente em Paulo Afonso - BA, a luz da Constituição Federal de 1988 e do Estatuto da Criança e Adolescente - ECA.

\section{Método}

As ciências sociais têm contribuído para uma melhor compreensão sobre: as relações sociais, como entender o cotidiano e direcionar acerca das estratégias de mudanças. Portanto, é preciso ter claro os métodos adequados ao se estudar os fatos sociais.

A pesquisa aconteceu no Estado da Bahia, Município Paulo Afonso, na perspectiva de identificar o grau de participação social no conselho municipal de direito da criança e do adolescente e quais são suas técnicas.

A base desse estudo foi centrada na pesquisa qualitativa. Para fundamentação do tema abordado foram usados também dois meios clássicos de pesquisa, a bibliográfica e a documental.

Para solucionar a problemática em questão serão analisados os trabalhos desenvolvidos por um Conselho Municipal que defende os direitos infanto-juvenis e o controle social que exerce face a representatividade democrática na gestão pública local, bem como o levante de ações que demonstrem a participação social no planejamento de políticas públicas para infância e adolescência.

Como meio de observação do contexto social estudado se fez necessário uso da pesquisa de campo, através de acompanhamento das reuniões ordinárias realizadas pelo conselho e aplicação de questionário aos conselheiros titulares e ao presidente do conselho.

Os questionários foram aplicados em reunião do referido Conselho, e continham perguntas que trabalhavam a consciência do conselheiro quanto o seu papel participativo e a demonstração do conhecimento das atividades realizadas pelo órgão.

De semelhante modo as reuniões serviram como excelente campo de observação. Através delas foi possível analisar a assiduidade dos conselheiros e suas opiniões sobre assuntos pertinentes. 
Id on Line Revista Multidisciplinar e de Psicologia

Id on Line Multidisciplinary Journal and Psycology

\section{Democracia e Participação Social}

A democracia é um caminho para o desenvolvimento de uma sociedade mais justa e igualitária, através de um governo do povo e voltada para o povo. Esta se tornou mais importante que nunca, devido ao cenário atual da sociedade desigual em seus direitos. Segundo Costa (2010), pode-se entender a democracia:

“[...] como o regime de governo que, legitimado pela soberania popular, exerce validamente seu poder decisório com base em um conjunto de regras preestabelecidas e aceitas pela ordem social". (COSTA, 2010, p. 88).

Com a Constituição Federal de 1988 a participação social tornou-se um fato, a sociedade civil organizada pode participar da implantação e gestão das políticas públicas, assumindo uma interlocução com o governo, não apenas para garantia de direitos, mas para dividir as responsabilidades nas decisões públicas.

Com a instituição do Estado Democrático de Direito a nação passou a ser uma República. De forma simples, significa dizer que o Estado não poderia ser regido por normas aristocráticas e o poder passara da mão de um soberano para a mão do soberano mor: O Povo.

Diante dessa nova formatação se prevê a caminhada para um Estado mais uniforme e justo com os anseios e necessidades de sua população. Um Estado sem benfeitorias para um grupo fechado de pessoas, mas com o ideal supremo de prover o bem estar social de seu povo. Agora, a sociedade é a responsável pelas decisões estatais, isso porque ela é quem, através da representatividade, escolhe seus governantes e tem poder para mantê-los ou destituí-los.

Falar de republicanismo é muito mais que apenas definir uma forma de Estado, segundo Costa (2010) é:

[...] falar em democracia e em direitos humanos, em exercício do poder do Estado e na dinâmica social. É falar em liberdade, igualdade e fraternidade, tanto quanto em eletividade, periodicidade e responsabilidade. É falar em participação popular, ética e em engajamento cívico. (COSTA, 2010, p. 16)

Para assegurar a liberdade, a fraternidade e, sobretudo, a igualdade é necessário que exista o engajamento da população. Uma participação que não se resume apenas na eleição de seus representantes, mas na composição de órgãos de influência nas decisões.

No entanto, diante do conceito de República, Democracia e participação popular e da realidade que o país enfrenta não se pode enfatizar que tais institutos são leais ao que preconiza o 
Estado Democrático de Direito, pelo menos ao que se refere a participação popular genuína. O estudo de tais institutos reveste o estudioso de otimismo participativo, mas é necessário que se considere o que fora dito por Pizzirani (2006):

No entanto, temos que ser bastante cuidadosos quando trabalhamos com esse processo e colocamos nele uma dose exagerada de otimismo e militantismo, transpondo para o processo a idéia de um instrumento emancipatório e libertador. Temos que nos lembrar que essa ainda é uma participação comandada pelo Estado. É o Estado que produz, induz e organiza a participação que presenciamos hoje [...] (PIZZIRANI, 2006, p. 111)

É necessário que esses órgãos influentes e que se baseiam no caráter paritário seja genuínos quanto a sua formação e funcionamento, pois fugindo do propósito participativo se tornam meros órgãos fantoches do poder estatal.

Deste modo, a participação social relacionada à tomada de decisões diretas se apresenta por representatividade, quer pelo voto direto ou pela indicação do Estado ou de Organizações da Sociedade Civil (OSC's).

\section{A Participação Social nos Conselhos Municipais da Criança e do Adolescente}

O engajamento da sociedade nos trabalhos de proteção de direitos da criança e do adolescente revela o progresso que as comunidades atuais atingiram se comparadas às comunidades antecedentes.

Quando se defende a criança e o adolescente se protege toda a sociedade. Surge aqui o compromisso para a comunidade ser mais participativa, por uma questão de dever, de exercício da democracia. A comunidade é co-responsável, juntamente com a família, poder público e sociedade em geral por assegurar os direitos fundamentais desses destinatários, conforme elenca o Estatuto da Criança e do Adolescente (ECA) em seu art. $4^{\circ}$, que diz:

É dever da família, da comunidade, da sociedade em geral e do Poder público assegurar, com absoluta prioridade, a efetivação dos direitos referente à vida, à saúde, à alimentação, à educação, ao esporte, ao lazer, à profissionalização, à cultura, à dignidade, ao respeito, à liberdade e à convivência familiar e comunitária. (Estatuto da Criança e do Adolescente, 1990).

A política de atendimento adotada pelo ECA defende a interação entre ações governamentais e não governamentais nas esferas federal, estadual e municipal, como resultado do pacto federativo instituído pela Carta Magna de 1988. 
Id on Line Revista Multidisciplinar e de Psicoloqia

Id on Line Multidisciplinary Journal and Psycology

Para alcance imediato desse propósito estipula a municipalização do atendimento através da criação de Conselhos municipais e fundo municipal para investimento nas ações específicas. Fortalecer o atendimento local é decisão que traz celeridade e eficácia para essas ações.

Art. 88 II - criação de conselhos municipais, estaduais e nacional dos direitos da criança e do adolescente, órgãos deliberativos e controladores das ações em todos os níveis, assegurada a participação popular paritária por meio de organizações representativas, segundo leis federal, estaduais e municipais; (Estatuto da Criança e do Adolescente, 1990)

A participação popular paritária refere-se a uma participação em que o Estado e a Sociedade Civil Organizada estarão em igualdade quanto ao número de representantes e a tomada de decisões. Foi uma forma moderada encontrada para aproximar a população, ainda que de forma representativa, da zona de influência política e social.

Além dessa participação representativa os Conselhos Municipais, na execução de suas atividades e atribuições, têm que desenvolver uma política de participação mais ampliada com interação direta da comunidade, como é o caso dos fóruns realizados antes da elaboração do plano de ação, que tem por finalidade colher dados reais e próximos da população.

Em razão da busca pela efetivação das ações devidas às crianças e adolescentes e da propagação de todos os direitos que lhes são conferidos é que os Conselhos Municipais surgiram, numa organização paritária entre governo e sociedade civil com a finalidade de deliberar e controlar as ações estatais de cunho local.

Estudo de Caso: Conselho Municipal dos Direitos da Criança e do Adolescente (CMDCA) Paulo Afonso - BA

O Conselho Municipal dos Direitos da Criança e do Adolescente - CMCDA de Paulo Afonso foi criado em 2003, através da Lei Municipal no 957/2003. É órgão da política de atendimento do Município, juntamente com o Conselho Tutelar e o Fundo Municipal dos Direitos da Criança e do Adolescente (FMDCA).

Enquanto o primeiro preserva a participação social na gestão pública devido a co-participação de responsabilidade do Estado para a sociedade civil organizada, o segundo assegura o cumprimento dos direitos inerentes às crianças e o adolescente, e o terceiro capta, repassa e aplica os recursos destinados ao desenvolvimento de ações de atendimento aos destinatários em situação de risco social e pessoal. 
O CMDCA tem função considerada de interesse público relevante, é formado por doze conselheiros, seis representantes do Município e titulares das seguintes secretarias: Secretaria de Educação, Secretaria de Saúde, Secretaria de Desenvolvimento Social, Secretaria de Administração e Finanças, Secretaria de Infraestrutura e Meio Ambiente e Secretaria de Cultura, Esporte e Turismo; e seis representantes indicados pelas organizações representativas da sociedade civil organizada de defesa dos direitos da criança e do adolescente. Seus membros exercem mandato de dois anos, podendo ser reconduzidos mais uma vez por igual período, sem remuneração.

O CMDCA foi fundamental na organização da funcionalidade das organizações civis cadastradas, transformando o que outrora se conhecia por ação altruísta em garantia de direitos.

O fortalecimento desses atos é reflexo da interação entre Estado e Sociedade. Essa interação ocorre nas reuniões realizadas pelos conselheiros, espaço onde os debates são organizados de acordo com as demandas presentes. Dessas reuniões saem as decisões, que se propagam nos resultados dos projetos, campanhas e capacitações.

Os projetos são selecionados a partir de um chamamento público por meio de edital em que as entidades da Sociedade Civil, com trabalho específico na área da assistência à criança e ao adolescente, os submetem à apreciação do Conselho. O CMDCA tem por prioridade:

\footnotetext{
Selecionar projetos de cunho social, de caráter inovador, com o objetivo de incentivar, apoiar, promover, atender, valorizar e dar visibilidade a práticas das entidades não governamentais devidamente registradas no CMDCA e que contribuam para a promoção, garantia, defesa, atendimento de crianças e adolescentes. (Edital CMDCA nº 01/2014 de 30 de janeiro de 2014).
}

Os projetos enviados precisam passar por comissões, formadas pelos membros do próprio Conselho, são elas: Comissão de Monitoramento e Avaliação dos Serviços Socioassistenciais e a Comissão Orçamentária e Financeira.

Tais comissões fazem uso de critérios que analisam a documentação da Entidade e/ou programa, quanto ao objeto do projeto, que deve ser claro, coerente e objetivo, além de estar em conformidade com Estatuto da Criança e do Adolescente. Outra análise importante é a que se refere ao público alvo, quantidade de beneficiados e a capacidade de ampliação desses projetos. 
Id on Line Revista Multidisciplinar e de Psicoloqia

Id on Line Multidisciplinary Journal and Psycology

\section{Resultados e Discussões}

A CMDCA encontra-se instalado na casa dos conselhos, lugar onde todos os conselhos existentes no Município de encontram. A instalação fixa foi cedida pelo município, com estrutura física adequada para o bom funcionamento dos conselhos municipais.

No ano de 2014 o CMDCA de Paulo Afonso favoreceu a execução de cinco projetos. Todos eles financiados pelo Fundo Municipal do Direito da Criança e do Adolescente - FMDCA, a saber:

I. O Convênio n ${ }^{\circ}$ 03/2014 celebrado entre o Município de Paulo Afonso e a Fundação de Amparo ao Menor de Paulo Afonso - FUNDAME tem como tema : OLHAR SOCIAL: UMA CÂMERA NA MÃO E VÁRIAS IDEIAS NA CABEÇA. Visa registrar a realidade do jovem pauloafonsino por meio da produção de documentários de curta metragem, abordando a história da FUNDAME, gravidez na adolescência, desnutrição infantil, drogadição e a realidade de crianças e adolescentes com necessidades especiais. O valor financiado foi de $\mathrm{R} \$ 39.997,00$, para as despesas deste projeto no período de abril a dezembro de 2014, atendendo 30 adolescentes, de 14 a 17 anos de ambos os sexos.

II. O Convênio celebrado entre o Município de Paulo Afonso e a Associação de Pais e Amigos dos Excepcionais, de $n^{\circ}$ 04/2014, tem como tema: VIVA A MÚSICA. Visa atender noventa e cinco crianças e adolescentes de ambos os sexos, com deficiência intelectual e múltipla com o intuito de estimulá-las no desenvolvimento de competências, habilidades e atitudes para a melhoria da qualidade de vida, exercício da cidadania, inclusão social e educacional com a formação de grupo de percussão para realizar apresentação na comunidade. O valor financiado foi de $\mathrm{R} \$ 39.960,00$, para as despesas deste projeto no período de abril a dezembro 2014.

III. Terceira aprovação foi do Convênio de cooperação técnica e financeira $n^{\circ}$ 005/2014, que entre si celebram o Município de Paulo Afonso e o CERSPA - Centro Evangélico de Recuperação Social de Paulo Afonso com recurso do FMDCA - Fundo Municipal do Direito da Criança e Adolescente, com título do projeto: EDUCANDO PELO ESPORTE. Visa atender sessenta crianças e adolescente com idade de 07 a 14 anos de idade, de ambos os sexos, e suas famílias, que se encontram em situação de vulnerabilidade socioeconômica do município de Paulo Afonso/BA, promovendo a inclusão social, e o desenvolvimento integral através da modalidade de Jiu-Jítsu, incentivando práticas esportivas como veículo de formação física, intelectual e social, estimulando a frequência e melhoria do rendimento escolar. O valor financiado foi de $\mathrm{R} \$ 39.999,95$, para as despesas deste projeto no período de abril a dezembro de 2014.

IV. Convênio de cooperação técnica e financeira $n^{\circ} 006 / 2014$, que entre si celebram o Município de Paulo Afonso e FUNDAME - Fundação de Amparo ao menor de Paulo Afonso com 
Id on Line Revista Multidisciplinar e de Psicoloqia

Id on Line Multidisciplinary Journal and Psycology

recurso do FMDCA - Fundo Municipal do Direito da Criança e Adolescente, com título do projeto: SONS DO CORAÇÃO: A arte de cantar, com objetivo de atender sessenta crianças e adolescentes, com faixa etária de 07 a 17 anos de ambos os sexos, moradores dos bairros adjacentes: Centenário, Sal Torrado e Senhor do Bomfim, fomentando o desenvolvimento das relações interpessoais entre as crianças e adolescentes através da música como elemento de transformação, cognitivo, psicomotor, oportunizando um espaço em que possam expressar sentimentos e pensamento, promovendo o fortalecimento dos vínculos familiares e comunitário. O valor financiado foi de $\mathrm{R} \$ 40.000,00$, para as despesas deste projeto no período de abril a dezembro de 2014 .

V. Convênio de cooperação técnica e financeira $n^{\circ}$ 007/2014, que entre si celebram o Município de Paulo Afonso e a Sociedade São Vicente de Paulo - Lar da Criança Vicentina, com recurso do Fundo Municipal do Direito da Criança e Adolescente, com título do projeto: MISTURARTE - Dialogando com a música, a dança e o teatro, atendendo cento e vinte crianças e adolescentes, com idade de 10 a 17 anos em situação vulnerabilidade social, promovendo uma transformação social, desenvolvendo a sensibilidade e a criatividade por meio da linguagem artística musical, oportunizando melhoria nas relações interpessoais. O valor financiado foi de $\mathrm{R} \$ 39.991,02$, para as despesas deste projeto no período de abril a dezembro de 2014.

Além dos projetos supracitados o Conselho desenvolve ações diversas, como: parceria com outros órgãos na realização de campanhas preventivas, realização de seminários para discussão junto à comunidade de tema de interesse social, e que após condensação dos debates irão gerar planos, pactos e projetos decisivos.

O trabalho do CMDCA, compreendido entre os projetos exemplificados acima e as ações realizadas, e de toda rede de atendimento dos direitos da criança e do adolescente de Paulo Afonso rendeu ao Município a conquista do Selo UNICEF (Fundação das Nações Unidas para a Infância), edição 2013-2016, dando continuidade ao título anterior (edição 2009-2012), bem como a representação do Brasil em evento realizado pela UNICEF na Jamaica em maio de 2014.

Para a titulação do Selo a UNICEF usa uma metodologia que estimula o desenvolvimento de políticas públicas nos municípios, é uma maneira notória de orientar as cidades a pactuar uma missão que corrobore para o desenvolvimento social e intelectual da criança e do adolescente. Uma missão que vai além da grafia crua dos projetos, mas que se transforme em atividade visível e palpável e, isso só é possível por meio da execução de programas e projetos imbuídos de responsabilidade.

Os municípios que tem o reconhecimento do Selo UNICEF são aqueles que fortaleceram e:

[...] desenvolveram e executaram políticas públicas e ações conjuntas, entre governo e sociedade civil, que melhoraram concretamente as condições de vida das crianças e dos adolescentes. Essas melhorias são constatadas pelos avanços efetivos em seus indicadores sociais. A estratégia do Selo UNICEF requer do município mudanças 
reais em três áreas: a) na vida das crianças (são as chamadas mudanças de "impacto social"); b) na gestão de políticas públicas; e c) na participação social no esforço para encontrar soluções e saídas para os principais problemas da comunidade. (Selo UNICEF Município aprovado Semiárido - Resultado do Selo 2009/2012)

Juntamente com seus parceiros e a administração pública em suas três instâncias a UNICEF busca promover mudanças eficazes na vida do público infanto-juvenil, na gestão de políticas públicas, bem como na participação social, este último é fator importantíssimo para a promoção das mudanças almejadas. Mesmo com seu caráter representativo a participação social tem ganhado prestígio, por transparecer, como um reflexo, os anseios de uma sociedade que deseja transformar aquilo que vivencia.

A visão da UNICEF quanto a essencialidade do engajamento cívico deixa claro o quanto esse instituto é decisivo na resolução de problemas e no melhoramento da rede de proteção as crianças e aos adolescentes.

Ainda sobre a metodologia do Selo UNICEF, que é o indicador máximo da realidade do município na seara dos direitos da criança e do adolescente, é importante listar os caminhos utilizados por ele na escolha das cidades reconhecidas. São dez caminhos, a saber:

I. Inscrição do Município;

II. Os municípios são agrupados de acordo com seus indicadores;

III. O selo avaliará os indicadores a partir do sistema nacional de dados;

IV. Os indicadores sociais são usados para a política de gerenciamento, planejamento e monitoramento, com a finalidade de melhorar os serviços básicos e saúde, educação e proteção social;

V. Realização de Fórum Comunitário no município, usado para realizar o diagnóstico local, onde ao final é desenvolvido um plano de ação;

VI. Os beneficiários também são inseridos na discussão de prioridades, e estimulados a produzir materiais de comunicação e mobilização com a comunidade;

VII. O UNCEF articula o comprometimento da administração estadual e federal no apoio às iniciativas municipais;

VIII. Realização do $2^{\circ}$ Fórum Comunitário, que tem por finalidade avaliar a execução do plano de ação e interagir com a comunidade quanto aos avanços conseguidos no período;

IX. Análise das informações enviadas pelo município e comparação destas com o sistema de dados nacional;

X. Por fim, os municípios que demostram o avanço de seus indicadores na área são reconhecidos como Município Aprovado. 
Id on Line Revista Multidisciplinar e de Psicoloqia

Id on Line Multidisciplinary Journal and Psycology

Diante de todo esse percurso é inevitável a participação da comunidade, pois é por meio de sua visão que os planos serão traçados, fortalecidos e executados. A premiação é um reconhecimento louvável, mas o que se realizou para obtê-la é ainda mais importante.

A participação social é um desses caminhos, pois em seu seguimento tem tanto o engajamento da comunidade direta, como a inclusão da comunidade representada no Conselho. Sua mobilização é visível não apenas na organização paritária do Conselho, mas no envolvimento entre as crianças e adolescentes, a sociedade civil organizada, a comunidade escolar e a sociedade em geral.

O CMDCA é o órgão que tem por tarefa empreender esses caminhos e garantir, por meio de sua rede, os indicadores cobrados pelo Selo, quais sejam: impacto social, gestão de políticas públicas e participação social, que também são os eixos utilizados pelo Selo em questão.

A pesquisa foi realizada no Município de Paulo Afonso com 50\% representantes do governo municipal e 50\% representantes da sociedade civil organizada, sendo que os representantes do governo são escolhidos por indicação e os representantes da sociedade civil são escolhidos por eleição. O estudo demonstrou que $66,67 \%$ dos entrevistados são sexo masculino e $33,33 \%$ do sexo feminino. No quesito de participação CMDCA, 8,33\% dos conselheiros participam há 7 anos; 16,67\% dos conselheiros participam há 6 anos; 8,33\% dos conselheiros participam há 5 anos; 8,33\% dos conselheiros participam há 4 anos; 25\% dos conselheiros participam há 3 anos e 33,33\% dos conselheiros participam há 2 anos.

Foi constatada na pesquisa que $100 \%$ dos entrevistados consideram fundamental a participação da sociedade civil no conselho como também os mesmos consideram a participação social como exercício da democracia e ainda os $100 \%$ dos entrevistados entende que a participação social no CMDCA assegura políticas públicas específicas. Observou-se que 100\% dos entrevistados conhecem as entidades cadastradas hoje no CMDCA.

A interlocução entre os representantes da sociedade civil organizada e poder público, deve ser constante, com diálogo aberto e trocas de conhecimentos, a fim de proporcionar objetividade e legitimidade às decisões.

Faz-se necessário que os conselheiros de direito busquem sempre refletir sobre a prática desenvolvida nesses espaços. Estabelecendo a renovação dessas práticas, que haja o despertar para uma participação continuada, com discussões conscientes e críticas, clareza nas decisões e posicionamento democrático, levando os conselheiros ao exercício e fortalecimento da cidadania. 
Id on Line Revista Multidisciplinar e de Psicoloqia

Id on Line Multidisciplinary Journal and Psycology

\section{Considerações Finais}

A criação de Conselhos municipais com caráter paritário potencializou a funcionalidade do Estado Democrático de Direito, estabelecendo a comunicação participativa entre governo e sociedade. Tal participação motivou o fortalecimento e ampliação das políticas públicas reservadas aos destinatários finais.

Essa conquista, apesar de local, incide sobre toda a política de atendimento do Brasil. Podendo-se concluir que quando a sociedade civil participa de forma organizada consegue influenciar na tomada de decisões, além de cumprir uma determinação que lhe é conferida pela Carta Magna Nacional. Lembrando que o progresso não seria possível sem o exercício da democracia e do engajamento cívico na gestão pública

Por fim, a experiência acumulada pelo CMDCA de Paulo Afonso é motivadora de toda a rede de atendimento de defesa dos direitos da criança e do adolescente do Brasil, uma vez que se tornou referência ao receber o Selo UNICEF.

É importante ressaltar que por traz de todo esse reconhecimento existe uma série de requisitos técnicos que o município teve que atender, e é por ter preenchido tais requisitos, que se pode enquadrar o Conselho como órgão diretor no desenvolvimento dessas atividades reconhecidas, que são: o impacto social transformador da realidade das crianças e adolescentes, a gestão de políticas públicas, e o principal foco desse estudo que é a participação social.

\section{Referências}

ALBUQUERQUE, Paulo Antônio de Menezes; MOREIRA, Márcio Alan Menezes. A democracia no estado moderno: entre ambivalência e participação. Pensar, Fortaleza, v.10, n. 10, p. 82-89, fev. 2005.

COSTA, Fábio Silva. Estado, direito e sociedade. Perspectivas para uma teoria republicana brasileira./ Fábio Silva Costa./ Curitiba: Juruá, 2010.

COSTA, S.F., Método Científico - os caminhos da investigação. 1 ed. São Paulo: Harbra, 2001.

CHIZZOTTI, Antonio. Pesquisa em Ciências Humanas e Sociais. 6.ed. São Paulo: Cortez, 2003.

D'ANDREA, Giuliano. Noções de direito da criança e do adolescente / Giuliano D'Andrea. Florianópolis : OAB/SC Editora, 2005.

DALLARI, Dalmo de Abreu, 1931 - Direitos humanos e cidadania / Dalmo de Abreu Dallari. - 2. ed. reform. - São Paulo : Moderna, 2004. - (coleção polêmica). 
Id on Line Revista Multidisciplinar e de Psicoloqia

Id on Line Multidisciplinary Journal and Psycology

GIL, A. C. Métodos e Técnicas de Pesquisa Social. 5ª Ed. São Paulo: Atlas, 1991.

KOCHE, José Carlos. Fundamentos de metodologia científica: teoria da ciência e iniciação à pesquisa. - Petrópolis, RJ: Vozes, 1997.

LAKATOS, Eva Maria \& MARCONI, Marina de Andrade. Fundamentos da Metodologia Científica. 4. ed. rev. e ampl. São Paulo: Atlas, 2001.

MINAYO, M. C. S. (org.). Pesquisa Social: teoria, método e criatividade. Petrópolis, RJ: Vozes, 1994.

PAULO AFONSO-BA. Lei Municipal n 1.215 de 02 de setembro de 2011. Dispõe sobre a política municipal dos direitos da criança e do adolescente, e dá outras providências.

Portal Paulo Afonso.ba.gov.br. Disponível em:

<http://www.pauloafonso.ba.gov.br/internas/informativos/read.php?id=3852> Acesso em: 14 de outubro de 2014.

Portal Paulo Afonso.ba.gov.br. Disponível em:

$<$ http://www.pauloafonso.ba.io.org.br/diarioOficial/download/587/1086/0 > Acesso em: 14 de outubro de 2014.

Portal Jusbrasil.com.br. Disponível em:

<http://www.jusbrasil.com.br/topicos/10608034/artigo-88-da-lei-n-8069-de-13-de-julho-de-1990>

Acesso em: 08 de setembro de 2014.

Portal mpgo.mp.br. Disponível em:

<http://www.mp.go.gov.br/portalweb/hp/7/docs/declaracao universal dos direitos do homem.pdf $>$

Acesso em: 08 de setembro de 2014.

Portal Planalto.gov.br. Disponível em:

$<$ http://www.planalto.gov.br/ccivil_03/constituicao/constituicao.htm> Acesso em: 24 de junho de 2014.

Portal selounicef.org.br. Disponível em:

$<$ http://www.selounicef.org.br/_selounicef.php?op=1\&k=1> Acesso em: 07 de novembro de 2014.

PRESTES, Maria Luci de Mesquita. A pesquisa e a construção do conhecimento científico: do planejamento aos textos, da escola à academia. - São Paulo: Rêspel, 2003.

Taylor, F. Winslow. Administração cientifica

RAICHELIS, Raquel. Democratizar a gestão das políticas sociais - Um desafio a ser enfrentado pela sociedade civil. Serviço Social e Saúde: Formação e Trabalho Profissional, Brasília, p. 1-17, 2000. 
Id on Line Revista Multidisciplinar e de Psicoloqia

Id on Line Multidisciplinary Journal and Psycology

\section{Como citar este artigo (Formato ABNT):}

SANTOS, F. E; NASCIMENTO, D.C. O exercício da democracia através da participação Social nos conselhos Municipais de Direito da criança e do Adolescente: Estudo de Caso no Município de Paulo Afonso - BA. Id on Line Revista Multidisciplinar e de Psicologia, Julho de 2016, vol.10, n.30, Supl 3, p. 99-112. ISSN 19811179 .

Recebido: 22/06/2016

Aceito: $13 / 07 / 2016$ 